\title{
Likelihood ratio of computed tomography characteristics for diagnosis of malignancy in adrenal incidentaloma: systematic review and meta-analysis
}

\author{
Fatemeh Alsadat Sabet ${ }^{1}$, Reza Majdzadeh ${ }^{2}$, Babak Mostafazadeh Davani ${ }^{3}$, Kazem Heidari ${ }^{4}$ and Akbar Soltani ${ }^{3^{*}}$
}

\begin{abstract}
Purpose: To propose an evidence based diagnostic algorithm using mass characteristics to determine malignancy in patients with adrenal incidentaloma by CTscan.

Methods: A systematic review in Medline, Scopus, relevant reference books and desk searching was performed up to January 2016 with relevant reference checking. The summery estimates of sensitivity, specificity, positive and negative likelihood ratio of different characteristics were calculated in two groups of the articles investigating the cases without previous malignancy and the articles investigating the oncologic cases.

Results: Thirty six articles were included in this study. In the first group with no history of malignancy a positive and negative LR of 3.1 and 0.13 in $4 \mathrm{~cm}$ threshold and positive and negative LR of 2.85 and 0 in $10 \mathrm{HU}$ density were found. In the second group with history of malignancy positive and negative LR of 2.3 and 0.27 in $3 \mathrm{~cm}$ threshold and positive and negative LR of 3.6 and 0.08 in $20 \mathrm{HU}$ density were resulted.

Conclusion: The results retrieved in this study considering the limitations show that adrenal incidentaloma with a size less than $4 \mathrm{~cm}$ or a mass larger than $4 \mathrm{~cm}$ with density less than $10 \mathrm{HU}$ in the first group can be managed with imaging follow up. For masses larger than $4 \mathrm{~cm}$ with density more than $10 \mathrm{HU}$ another diagnostic procedure should be performed. In the second group an adrenal mass larger than $3 \mathrm{~cm}$ or less than $3 \mathrm{~cm}$ with density more than $2 \mathrm{HU}$ should go under operation. But masses smaller than $3 \mathrm{~cm}$ with less than $20 \mathrm{HU}$ density can be followed by imaging.
\end{abstract}

Keywords: Adrenal incidentaloma, Malignancy, Systematic review, Likelihood ratio, HU Density

\section{Background}

Adrenal incidentaloma, a clinically silent adrenal mass, detected inadvertently during diagnostic tests or treatment for causes other than adrenal disease, was first described more than 20 years ago [1]. During recent years, widespread application of noninvasive and sensitive imaging techniques has led to an increased detection of incidentalomas [2-5]. These adrenal masses occur in $0.35-9 \%$ of all abdominal computerized tomography $(\mathrm{CT})$ scans $[2,3,6-8]$ that increases

\footnotetext{
*Correspondence: Soltania@tums.ac.ir

${ }^{3}$ Evidence based Practice Research Center, Endocrinology and Metabolism Research Center, Tehran University of Medical Sciences, Tehran, Iran

Full list of author information is available at the end of the article
}

to as much as $10 \%$ in the elderly [1] peaking in fifth and seventh decades [5]. In autopsies or cases of prior malignancy the prevalence of previously undetected adrenal tumors increases again $[3,4,8-10]$.

$36-94 \%$ of these masses are benign cortical adenomas $[3,4,9,11-15]$, and even in patients with a known carcinoma of any histology only $19-75 \%$ of the masses are metastatic $[7,8,15-18]$. However, because of high mortality rate of malignant lesions with less than 50 percent 5 -year overall survival for adrenal cortical carcinoma, it is needed to rule out these lesions $[7,11]$. The prevalence of adrenal carcinoma reaches to $3-17$ per million in general population, however, adrenal incidentaloma has a chance of $1.2-12 \%$ to be malignant $[7,8,19,20]$. 
The first step in the evaluation of an adrenal mass is to classify it as a hormonally active or a nonfunctional mass $[21,22]$. In the second step the mass should be verified for the risk of malignancy. Typical characteristics of benign adenomas on CT include smooth contour, sharp margin and small size, while typical features of carcinoma are heterogeneity, tumor calcification and large size $[23,24]$. The problem is that significant overlap with malignant lesions limits the usefulness of size as a criterion [25]. The nature of incidentally found adrenal masses is more questionable when the size is $3-6 \mathrm{~cm} \mathrm{[7,}$ 26-28]. It is important to keep in mind that with present strategies, the diagnosis process is not cost-effective with more than necessary rate of operation and the need for a better guideline is repeated in the literature [24, 29].

The aim of this study was to answer what are the Likelihood Ratios (LRs) of different characteristics of adrenal masses in CT scan as the method of choice to diagnose malignancy in patients with adrenal incidentaloma. Subsequently we purposed to suggest an evidence based flowchart for evaluation of malignancy of the adrenal mass by CT scan helping us to choose the best time for operation.

\section{Methods}

\section{Literature search and study selection}

In this study we searched Medline and Scopus databases from 1970 to January 2016 by structured search strategy including both text word and Medical Subject Heading (MeSH) term of any of the following headings: (adrenal incidentaloma OR adrenal mass) AND diagnostic search strategy [30]. Our complete search strategy in Medline database was:

(("adrenal incidentaloma"[Text Word] OR "adrenal incidentaloma"[Mesh] OR "adrenal mass"[Text Word] OR "adrenal tumor"[Text Word]) AND (("physical examination"[MeSH Terms] OR physical examination[Text Word]) OR ("medical history taking"[MeSH Terms] OR medical history taking[Text Word]) OR ("professional competence"[MeSH Terms] OR professional competence[Text Word]) OR ("sensitivity"[MeSH Terms] OR sensitivity[Text Word] OR specificity [MeSH Terms] OR specificity[Text Word]) OR ("reproducibility of results"[MeSH Terms] OR reproducibility of results[Text Word]) OR ("observer variation"[MeSH Terms] OR observer variation[Text Word]) OR ("routine diagnostic tests"[Text Word] OR "diagnostic tests, routine"[MeSH Terms] OR diagnostic tests[Text Word]) OR ("decision support techniques"[MeSH Terms] OR decision support techniques[Text Word]) OR ("bayes theorem"[MeSH Terms] OR Bayes theorem[Text Word]) OR ("predictive value of tests"[MeSH Terms] OR predictive value of tests[Text Word]) OR ("palpation"[MeSH Terms] OR palpation[Text Word]) OR ("percussion"[MeSH Terms] OR
percussion[Text Word]) OR ("diagnosis"[Subheading] OR "diagnosis, differential"[MeSH Terms] OR differential diagnosis[Text Word]) OR ("diagnostic errors"[MeSH Terms] OR diagnostic errors[Text Word])) AND ((Humans[Mesh Terms]) AND (English[lang])))

We used the same strategy for searching articles in Scopus database. Our search covered references of the related chapters of relevant textbooks [31-34] as well as desk searching. To be sure about the acceptable coverage of the study, the references of the selected articles were also reviewed and the relative articles among the references were chosen to be appraised. This method was continued until no more new articles were found.

Two independent reviewers (F.S. and B.M.) chose the potentially relevant articles retrieved by the search based on the previously set inclusion and exclusion criteria. According to the inclusion criteria the a) original articles b) published after 1970 c) which were in English d) discussed CT scan as the diagnostic test in which e) a gold standard test (operation, biopsy, FNA or follow up for more than 6 months) was performed for final diagnosis were selected. The other inclusion criteria of relevant full-texts were $f$ ) the presence of full explanation of imaging procedure that follows standard method of CT scanning and g) the presence of clearly described criteria for index test with accepted thresholds. Then the articles found a) overlapped with the others, b) the articles without any case of malignancy or c) without any case of benign mass or d) "case report" or "case series" articles with less than 15 subjects were excluded from the study. The reviewers reached agreement on all challenging studies for inclusion by face-to-face discussion.

\section{Quality assessment and data extraction}

The included articles underwent appraisal by two reviewers independently for quality based on Quality Assessment of Diagnostic Accuracy Studies standard checklist (QUADAS) [35] and consensus was reached through discussion for different opinions. QUADAS tool is an evidence-based checklist with 14 questions, developed for evaluation of diagnostic accuracy studies. In case of any disagreement remained after discussion we referred to the third reviewer opinion (A. S.). The extracted data from each study included date of publication, place and time in which the study was conducted, number of subjects, the range and mean of the age of the subjects, special characteristics of subjects, the reference test and the type of study whether it is retrospective or prospective. For imaging features mass size, appearance characteristics of the mass like heterogeneity, irregularity, smoothness of margin and calcification in non-contrast CT scan as well as Hounsfield Unit (HU) on $\mathrm{CT}$ scan were extracted and enhancement characteristics of the mass were specified. 
The studies were classified into two categories: the studies including true adrenal incidentalomas without any history of malignancy and the studies based on the subjects who had a prior history of neoplasm. The studies that did not separate these two groups of subjects clearly or surgical series that did not exclude known extra-adrenal malignant cases were included in second category to make sure that we have a collection of true adrenal incidentalomas in the first one. Available data on true positive (TP), false positive (FP), false negative (FN) and true negative (TN) were extracted to have the test-disease $2 \times 2$ table. If sensitivity and specificity were reported in the article the raw data were calculated based on total number of subjects.

\section{Statistical analysis}

The sensitivity and specificity of a) size of the mass, b) different appearance characteristics of the mass in CT scan, c) CT scan density of the mass (based on HU) and d) enhancement characteristics in both groups of the patients with and without prior history of malignancy were calculated for each article with a $95 \%$ confidence interval. The co-sensitivity and co-specificity (pooled sensitivity and specificity of the cases calculated by "midas" command) as well as pooled positive or negative likelihood ratios were reported. Positive LR equals to sensitivity divided by one minus specificity while negative LR equals to one minus sensitivity divided by specificity. The articles were considered homogenous for meta- analysis when the $\mathrm{I}^{2}$ was less than 50 considering its $95 \%$ confidence interval reported. The co-sensitivity, co-specificity and positive and negative likelihood ratio for diagnosing malignant masses of the adrenal gland were calculated using random effect model of "midas" command in "STATA" software [36, 37]. The adequate number of data for "midas" command to analyze was 4 articles so we only pooled data of at least 4 article categories.

\section{Result \\ Studies}

A total of 1614 studies in Medline and 2769 studies in Scopus were identified. 17 studies were found relevant to this study among references of text books of endocrinology and 8 studies were found in desk searching for diagnosis of malignancy of adrenal incidentaloma. We also found 98 references of review articles relevant to our study. The selection process was conducted based on the previously mentioned inclusion and exclusion criteria (Fig. 1) Finally 36 full texts of the articles were selected. (Table 1) The articles a) without acceptable quality using QUADAS scoring tool including the ones with inacceptable reference standards, (n:24), b) with number of subjects less than 15 (n:6), c) the studies with objectives irrelevant to our study or the imaging tool other than CT scan (n:26), d) the ones with inappropriate data reporting that did not let us to extract $2 \times 2$ table elements (n:39), e) the studies without any case of

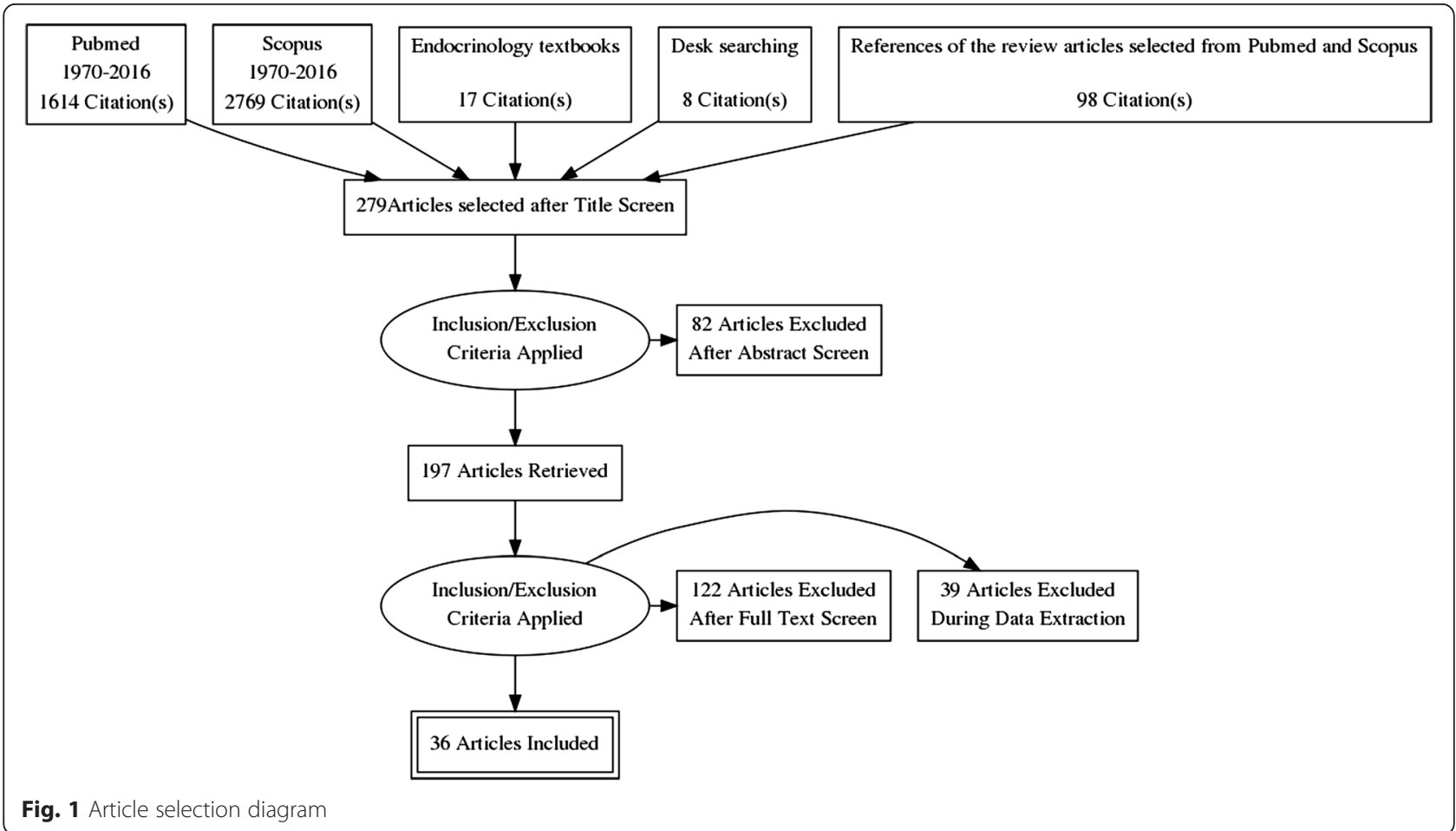


Table 1 Details of articles included in this study using CT scan as the imaging procedure

\begin{tabular}{|c|c|c|c|c|c|c|c|c|}
\hline Author & $\begin{array}{l}\text { Publication } \\
\text { date }\end{array}$ & $\begin{array}{l}\text { Country, (State), period of } \\
\text { conduction of the study }\end{array}$ & $\begin{array}{l}\text { Number of } \\
\text { subjects }\end{array}$ & $\begin{array}{l}\text { Age: Mean, } \\
\text { (range) }\end{array}$ & Description of the mass & Gold standard & $\begin{array}{l}\text { QUADAS score } \\
\text { (out of 14) }\end{array}$ & Type \\
\hline Birsen [61] & 2014 & USA (Ohio), 2000-2012 & 157 & & Non functional & Operation, follow up & 13 & retrospective \\
\hline Reginelli [62] & 2014 & Italy, 2011-2013 & 35 & $(25-89)$ & Non functional & Operation, follow up & 11 & retrospective \\
\hline Allan[63] & 2013 & USA (Florida), 2006-2010 & 49 & 51 & Functional & Operation & 12 & prospective \\
\hline Henning [64] & 2009 & $\begin{array}{l}\text { Sweden (Uppsala), } \\
\text { 2001-2003 }\end{array}$ & 38 & $\begin{array}{l}67.5,(45-81) 60, \\
(24-77)\end{array}$ & Non functional & Operation, follow up & 13 & $\begin{array}{l}\text { retrospective and } \\
\text { prospective }\end{array}$ \\
\hline Bhargav [65] & 2008 & India, 1991-2005 & 59 & $41,(13-58)$ & Functional & Operation, FNA & 10 & retrospective \\
\hline Vilar [66] & 2008 & Brazil, 2000-2007 & 52 & $50.3,(25-62)$ & Non functional & $\begin{array}{l}\text { Operation, FNA, } \\
\text { follow up }\end{array}$ & 12 & retrospective \\
\hline Park [67] & 2007 & Korea, 2001-2005 & 45 & $46.4,(16-72)$ & $\begin{array}{l}\text { Functional, Non } \\
\text { functional, Metastasis }\end{array}$ & Operation & 13 & retrospective \\
\hline Blake [68] & 2006 & $\begin{array}{l}\text { USA, (Massachusetts), } \\
\text { 2000-2002 }\end{array}$ & 99 & $66,(37-86)$ & $\begin{array}{l}\text { Non functional, } \\
\text { Metastasis, excluded } \\
\text { Pheo, Cyst, } \\
\text { myelolipoma }\end{array}$ & $\begin{array}{l}\text { Follow up, } \\
\text { operation, FNA }\end{array}$ & 13 & retrospective \\
\hline Meyer [69] & 2006 & $\begin{array}{l}\text { Germany (Hannover), } \\
\text { 1987-2001 }\end{array}$ & 52 & 56.4 & Non functional & Operation & 12 & retrospective \\
\hline Hamrahian [53] & 2005 & USA, (Ohio), 1997-2002 & 297 & $54,(42-66)$ & $\begin{array}{l}\text { Functional, } \\
\text { Non functional, } \\
\text { Metastasis }\end{array}$ & operation & 13 & retrospective \\
\hline Frilling [70] & 2004 & Germany (Essen), 1995-2003 & 42 & $58,(33-79)$ & $<6 \mathrm{~cm}$, Metastasis & Operation, FNA, & 11 & prospective \\
\hline Gufler [54] & 2004 & Germany (Siessen), 3 years & 56 & $56.2,(34-80)$ & metastasis & $\begin{array}{l}\text { Follow up, } \\
\text { operation, biopsy }\end{array}$ & 11 & retrospective \\
\hline Bulow [57] & 2002 & $\begin{array}{l}\text { Sweden (33 Swedish } \\
\text { hospitals), 1996-2001 }\end{array}$ & $\begin{array}{l}381(85 \\
\text { operated) }\end{array}$ & $64,(18-84)$ & $\begin{array}{l}\text { Functional, } \\
\text { Non functional, } \\
\text { Metastasis }\end{array}$ & operation & 10 & prospective \\
\hline Mantero [71] & 2000 & Italy, 1980-1995 & $\begin{array}{l}1004(380 \\
\text { operated })\end{array}$ & $58,(15-86)$ & Non functional & Operation, & 11 & retrospective \\
\hline Bergstrom [72] & 2000 & Sweden (Uppsala) & 15 & $(42-78)$ & $\begin{array}{l}>1 \mathrm{~cm} \text { Functional, } \\
\text { Non functional }\end{array}$ & Operation, biopsy & 11 & prospective \\
\hline Sworczak [73] & 2000 & Poland, 1994-1999 & 57 & 54.7, (34-79) & Non functional & Operation & 12 & prospective \\
\hline Tutuncu [74] & 1999 & Turkey, 1985-1995 & $33(17)$ & & $\begin{array}{l}\text { Functional, } \\
\text { Non functional }\end{array}$ & $\begin{array}{l}\text { Follow up, } \\
\text { operation, biopsy }\end{array}$ & 10 & retrospective \\
\hline Szolar [38] & 1998 & Austria & 122 & $64,(12-87)$ & $\begin{array}{l}\text { Functional, } \\
\text { Non functional, } \\
\text { Metastasis }\end{array}$ & $\begin{array}{l}\text { Follow up, } \\
\text { operation, biopsy }\end{array}$ & 12 & prospective \\
\hline $\begin{array}{l}\text { Kasperlik- } \\
\text { Zaluska [75] }\end{array}$ & 1997 & Poland, 1987-1997 & 208 & $52,(14-76)$ & Non functional, & $\begin{array}{l}\text { Operation }(>4 \mathrm{~cm}), \\
\text { follow up }\end{array}$ & 12 & prospective \\
\hline Boland [76] & 1997 & $\begin{array}{l}\text { USA, (Massachusetts), } \\
\text { 1995-1996 }\end{array}$ & 44 & $63,(21-88)$ & $\begin{array}{l}\text { Metastasis, } \\
\text { Non functional }\end{array}$ & $\begin{array}{l}\text { Follow up, } \\
\text { operation, biopsy }\end{array}$ & 12 & prospective \\
\hline
\end{tabular}


Table 1 Details of articles included in this study using CT scan as the imaging procedure (Continued)

\begin{tabular}{|c|c|c|c|c|c|c|c|c|}
\hline Szolar [39] & 1997 & Austria & 72 & $60,(12-83)$ & $\begin{array}{l}\text { Functional, } \\
\text { Non functional, } \\
\text { Metastasis }\end{array}$ & $\begin{array}{l}\text { Follow up, } \\
\text { operation, biopsy }\end{array}$ & 12 & prospective \\
\hline Angeli [77] & 1997 & Italy, 1980-1995 & $887(316)$ & $56,(15-89)$ & Non functional, & operation & 11 & retrospective \\
\hline $\begin{array}{l}\text { Mc Nicholas } \\
{[51]}\end{array}$ & 1995 & USA, (Massachusetts) & 37 & $63,(19-81)$ & Metastasis & Biopsy, Follow up & 13 & prospective \\
\hline Miyake [78] & 1994 & Japan & 34 & & $\begin{array}{l}\text { Non functional, } \\
\text { Metastasis }\end{array}$ & Operation, follow up & 12 & prospective \\
\hline Singer [79] & 1994 & USA, (Ohio), 1988-1991 & 21 & $66,(54-75)$ & $\begin{array}{l}\text { Functional, Non } \\
\text { functional, Metastasis }\end{array}$ & Operation, FNA & 11 & retrospective \\
\hline van Erkel [80] & 1994 & Netherland, 1985-1991 & 37 & $(21-77)$ & Non functional & Operation, follow up & 11 & prospective \\
\hline Candel [81] & 1993 & USA, (Illinois), 1985-1991 & 39 & $67,(29-80)$ & Metastasis & FNA & 12 & retrospective \\
\hline Semelka [82] & 1993 & North Carolina (USA) & 30 & $66.8,(21-82)$ & Not mentioned & $\begin{array}{l}\text { Operation, FNA, } \\
\text { follow up }\end{array}$ & 11 & prospective \\
\hline Lee [83] & 1991 & USA, (Massachusetts), 1988 & 55 & $52,(30-75)$ & $\begin{array}{l}>1 \mathrm{~cm},>-50 \mathrm{HU} \\
\text { Metastasis, } \\
\text { Non functional }\end{array}$ & $\begin{array}{l}\text { Follow up, } \\
\text { operation, biopsy }\end{array}$ & 12 & retrospective \\
\hline Herrera [84] & 1991 & USA, (Minnesota), 1985-1989 & 342 & $62,(2-86)$ & Non functional & $\begin{array}{l}\text { Operation, FNA, } \\
\text { follow up }\end{array}$ & 12 & retrospective \\
\hline Yamakita [85] & 1990 & Japan, 1964-1988 (1980-1988) & 379 & $(38-65)$ & Non functional & Operation & 11 & retrospective \\
\hline Lopez [86] & 1990 & Chile, 1984-1988 & 18 & $(21-80)$ & $\begin{array}{l}>6 \mathrm{~cm} \text {, Functional, Non } \\
\text { functional, Metastasis }\end{array}$ & operation & 12 & retrospective \\
\hline Hubbard [55] & 1989 & USA, (Tennessee), 1978-1987 & 28 & $(22-74)$ & Non functional & $\begin{array}{l}\text { Operation, FNA, } \\
\text { follow up }\end{array}$ & 12 & retrospective \\
\hline Paivansalo [40] & 1988 & Finland, 1980-1986 & 75 & $58,(2-83)$ & $\begin{array}{l}\text { Functional, Non functional, } \\
\text { Metastasis }\end{array}$ & Operation, follow up & 11 & prospective \\
\hline Katz [41] & 1985 & Texas, 1977-1983 & 16 & $(35-76)$ & Metastasis & FNA & 11 & prospective \\
\hline Hussain [42] & 1984 & USA, (Massachusetts), 1979-1983 & 43 & $38,(7-75)$ & $\begin{array}{l}\text { Functional, Non functional, } \\
\text { Metastasis }\end{array}$ & Biopsy, surgery & 11 & prospective \\
\hline
\end{tabular}


malignant or benign mass (n:5), f) review articles (n:59), g) the one that the subjects overlapped other studies and h) an article without appropriate method for subject selection were excluded in this level. We found two articles by Szolar in 1997 and 1998 [38, 39] that seemed overlapped but they are both included in the study extracting non-identical data from both because we did not receive any answer from the author asking about the potential overlap between subjects of studies.

\section{Pooling of data and meta-analysis}

Data were extracted in four main categories from the articles. These groups include size, appearance in CT scan, density of the mass based on $\mathrm{HU}$ and enhancement characteristics of the mass.

\section{Size}

Results of the pooled estimate of statistical measures of the test based on different size cut-offs of the adrenal mass in the first group of patients without extra-adrenal malignancy history shows the articles in all the size cutoff groups are heterogeneous except for the $4 \mathrm{~cm}$ cut-off in which because of wide range of $\mathrm{I}^{2}$ the result is considered non homogenous as well (Table 2). As it is predicted, sensitivity for detection of malignant masses decreases with progression in size while specificity has an increasing course which makes an obvious change in $4 \mathrm{~cm}$ cut-off. The forest plot and Summary Roc Curve (SROC) of articles in $4 \mathrm{~cm}$ size category as the best cutoff for malignancy detection based on previous studies [40-46] show the articles are heterogeneous but have appropriate test accuracy measures with an area under the curve (AUC) of 0.92 (Figs. 2 and 3). No publication bias was detected for this group of articles. (Begg's test $p$-value $=0.06$ for sensitivity and 0.64 for specificity)

In patients with prior history of malignancy, the results of pooled estimates in different size cut-offs show a decrease in sensitivity with an increase in specificity in progression of size as it was predicted. All size category articles are heterogeneous regarding high $\mathrm{I}^{2}$ (Table 3 ). Based on previous studies the best size cut-off in this category for detection of malignancy is $3 \mathrm{~cm}[3,44]$ with a distinct decrease in sensitivity and increase in specificity after it in this study. Forest plot shows heterogeneous articles and SROC shows an AUC of 0.77 in this size category (Figs. 4 and 5). No publication bias was detected for this group of articles. (Begg's test $p$-value $=$ 0.07 for sensitivity and 1 for specificity)

\section{Mass appearance}

The only category with proper number of studies for meta-analysis in adrenal mass CT appearance characteristics is heterogeneity in patients with prior malignancy that does not show significant positive and negative LR like other categories of mass appearance (Table 4). These results confirm low power of mass appearance for detection of malignancy.

\section{Mass density in CT scan}

In the first group of patients without malignancy history the number of the articles in each category was not enough (were less than 4) that meta-analysis could not be performed but in second group in 10 and $20 \mathrm{HU}$ thresholds the result of meta-analysis shows an increase in specificity without a marked change in sensitivity that favors $20 \mathrm{HU}$ cut-off (Table 5). Previous studies propose $10 \mathrm{HU}$ as the best cut-off in patients without history of malignancy $[45,47-50]$ and $20 \mathrm{HU}$ as the best threshold in patients with history of malignancy [44] The articles in $20 \mathrm{HU}$ mass density are heterogeneous based on forest plot resulted in this study (Fig. 6). SROC with an AUC of 0.93 shows an appropriate test accuracy measure (Fig. 7). No publication bias was detected for this group of articles. (Begg's test $p$-value $=0.30$ for sensitivity and 1 for specificity)

\section{Mass enhancement}

In 1997 Boland et al. reported sensitivity and specificity of 78 and $22 \%$ in delayed enhancement with $28 \mathrm{HU}$ threshold that reaches to 96 and $96 \%$ with a $15 \mathrm{~min}$ delay and a 24 HU cut-off. [51] In the other study Szolar et al. in 1998 found a sensitivity and specificity of 97 and $100 \%$ in $37 \mathrm{HU}$ after $30 \mathrm{~min}$ of enhancement and 100 and $97 \%$ in $42 \mathrm{HU}$ after 30 minutes [39]. Results of other articles studying enhancement did not show enough number of articles to perform meta-analysis (Table 6).

Table $\mathbf{2}$ LR for Size. Pooled estimate of sensitivity, specificity, positive and negative LR based on different size cut-offs of the adrenal mass in patients without prior history of malignancy

\begin{tabular}{lllllll}
\hline Cut-off & No of studies & Co-sensitivity $(95 \%$ Cl) & Co-specificity $(95 \%$ Cl) & $I^{2}(95 \% C l)$ & Pooled positive LR & Pooled negative LR \\
\hline $3 \mathrm{~cm}$ & 9 & $0.91,(0.83-0.95)$ & $0.44,(0.28-0.62)$ & $77,(50-100)$ & $1.6,(1.2-2.2)$ & $0.21,(0.10-0.42)$ \\
$4 \mathrm{~cm}$ & 11 & $0.91,(0.82-0.96)$ & $071,(0.55-0.83)$ & $77,(51-100)$ & $3.1,(2-4.9)$ & $0.13,(0.06-0.25)$ \\
$5 \mathrm{~cm}$ & 8 & $0.78,(0.67-0.87)$ & $0.82,(0.65-0.91)$ & $69(32-100)$ & $4.3,(2.1-8.9)$ & $0.26,(0.16-0.44)$ \\
$6 \mathrm{~cm}$ & 11 & $0.74,(0.63-0.82)$ & $0.85,(0.69-0.94)$ & $94(89-99)$ & $5.0,(2.4-10.8)$ & $0.31,(0.22-0.43)$ \\
\hline
\end{tabular}




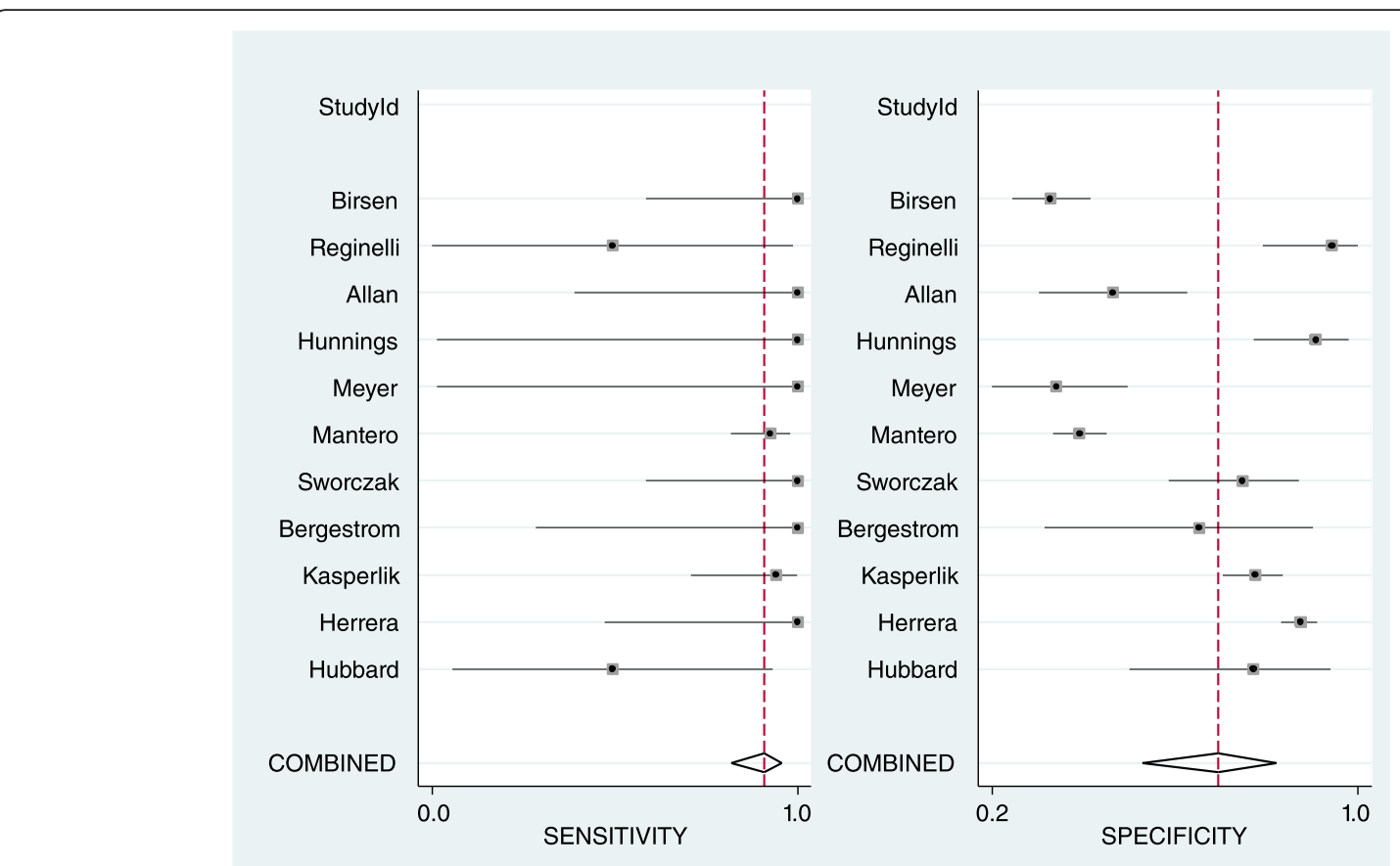

Fig. 2 Forest plot of $4 \mathrm{~cm}$ adrenal mass as the best cut-off in patients with adrenal incidentaloma without history of malignancy

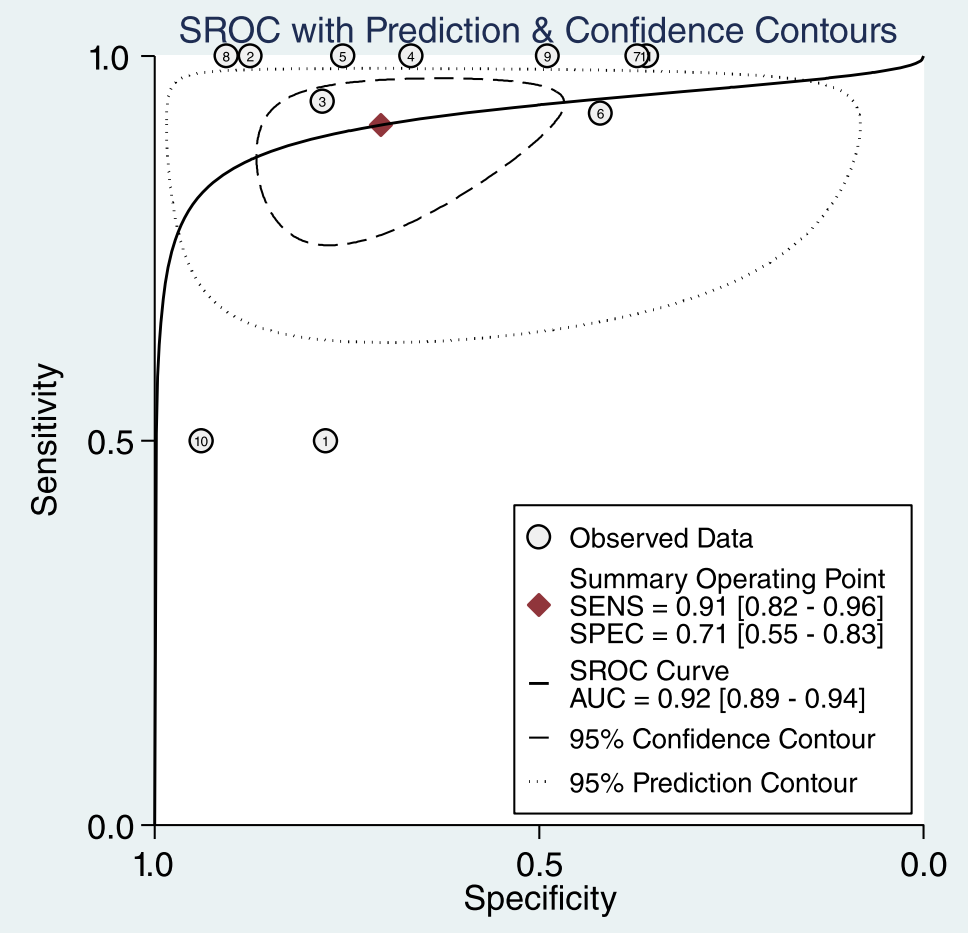

Fig. 3 SROC of $4 \mathrm{~cm}$ adrenal mass as the best cut-off in patients with adrenal incidentaloma without prior history of malignancy 
Table 3 LR for size: Pooled estimate of sensitivity, specificity, positive and negative LR based on different size cut-offs of the adrenal mass in patients with prior history of malignancy

\begin{tabular}{lllllll}
\hline Cut-off & No of studies & Co-sensitivity $(95 \% \mathrm{Cl})$ & Co-specificity $(95 \% \mathrm{Cl})$ & $\mathrm{I}^{2}(95 \% \mathrm{Cl})$ & Pooled positive LR & Pooled negative LR \\
\hline $1.5 \mathrm{~cm}$ & 1 & 0.93 & 0.16 & - & 1.1 & 0.43 \\
$2 \mathrm{~cm}$ & 2 & $0.95,1$ & $0.41,0.20$ & - & $1.61,1.25$ & $0.12,0$ \\
$2.5 \mathrm{~cm}$ & 3 & $0.79,1,0.84$ & $0.84,0.58,0.66$ & - & $4.93,2.38,2.47$ & $0.25,0,0.24$ \\
$3 \mathrm{~cm}$ & 7 & $0.83,(0.56-0.95)$ & $0.64,(0.45-0.79)$ & $92,(86-99)$ & $2.3,(1.5-3.5)$ & $0.27,(0.1-0.74)$ \\
$4 \mathrm{~cm}$ & 6 & $0.56,(0.35-0.75)$ & $0.85,(0.69-0.94)$ & $94,(89-99)$ & $3.8,(2.3-6.4)$ & $0.51,(0.35-0.75)$ \\
$5 \mathrm{~cm}$ & 6 & $0.31,(0.14-0.57)$ & $0.92,(0.80-0.97)$ & $93,(86-99)$ & $4,(1.9-8.3)$ & $0.74,(0.56-0.98)$ \\
$6 \mathrm{~cm}$ & 6 & $0.32,(0.11-0.63)$ & $0.92,(0.85-0.96)$ & $92,(85-99)$ & $4,(1.9-8.7)$ & $0.74,(0.51-1.08)$ \\
\hline
\end{tabular}

\section{Discussion}

The growing number of incidentally detected adrenal mass makes the diagnosis of malignant ones a challenge these days and lack of optimized diagnostic guidelines and controversies in this field represents the importance of new studies. In this study in the first group without prior history of malignancy a positive and negative LR of 3.1 and 0.13 and an area under the curve of 0.92 was found in $4 \mathrm{~cm}$ cutoff for detection of malignancy. The positive and negative LR are nor confirmative nor exclusive for malignancy that confirm other studies suggesting that other parameters beside size are needed for definite diagnosis [8, 45]. Although the size of the lesion is the first important known parameter to distinguish benign from malignant adrenal masses, it has a range of 3 to $6 \mathrm{~cm}$ for malignancy detection in different review articles because of the significant overlap between benign and malignant masses, but the most recent ones suggest $4 \mathrm{~cm}$ as the optimum size for operation $[43-48,52]$. As it was predicted the sensitivity of detection of malignant cases decreased with size progression while the specificity increases that supports previous studies [53-55].

In the second group with an extra adrenal history of neoplasm, positive and negative LR was 2.3 and 0.27 in turn which are not confirmative or exclusive. Based on the reports of other studies, the best size threshold of masses in patients with history of malignancy is $3 \mathrm{~cm}$ because the prevalence of metastatic lesion increases in these studies and a metastatic lesion can be found with variable sizes as an adrenal mass [3, 44]. The process of decreasing sensitivity and increasing specificity with higher sizes as it is predicted confirm previous studies.

In accordance with other studies, the appearance of the lesion including heterogeneity, rough margins,

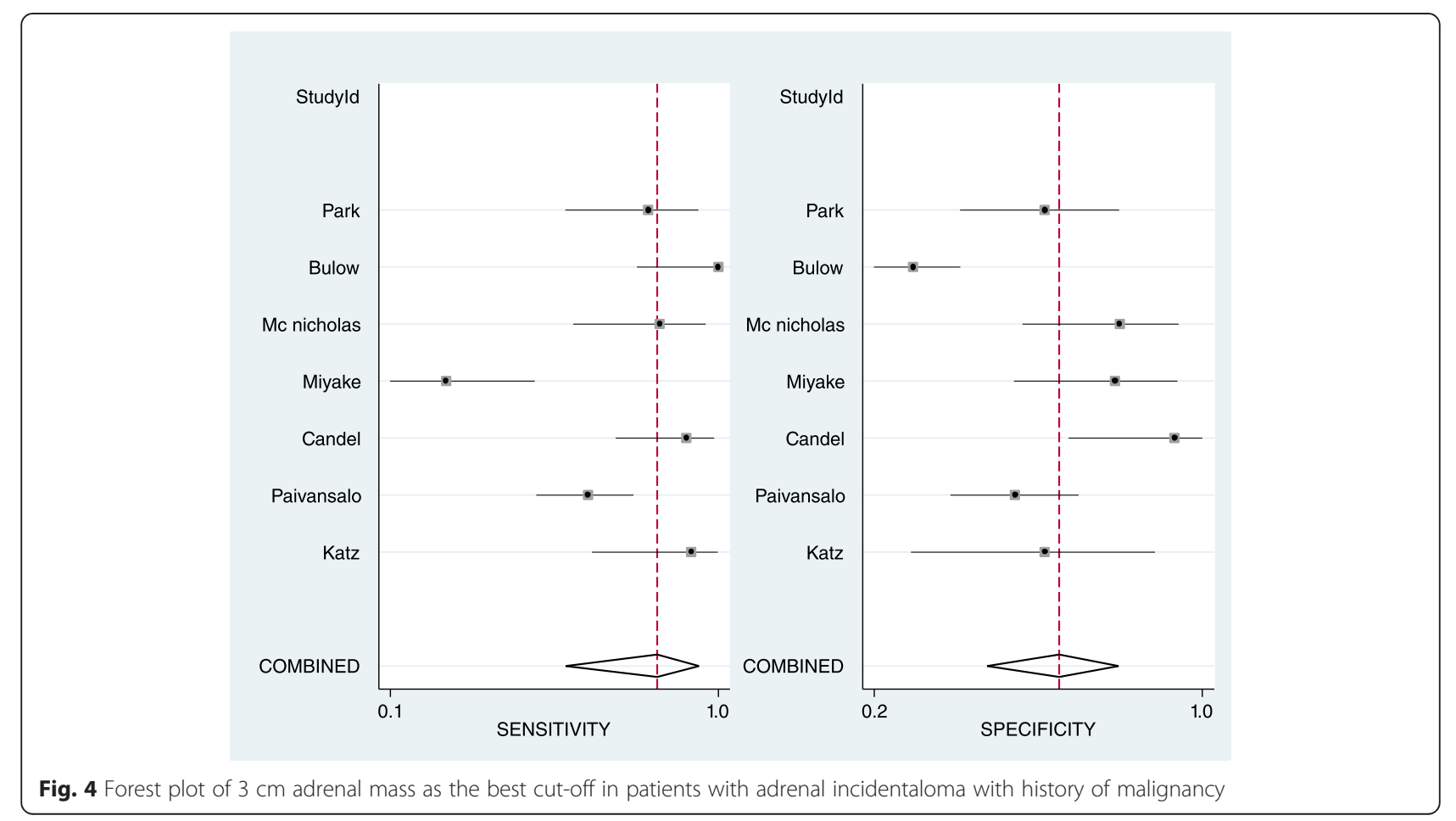




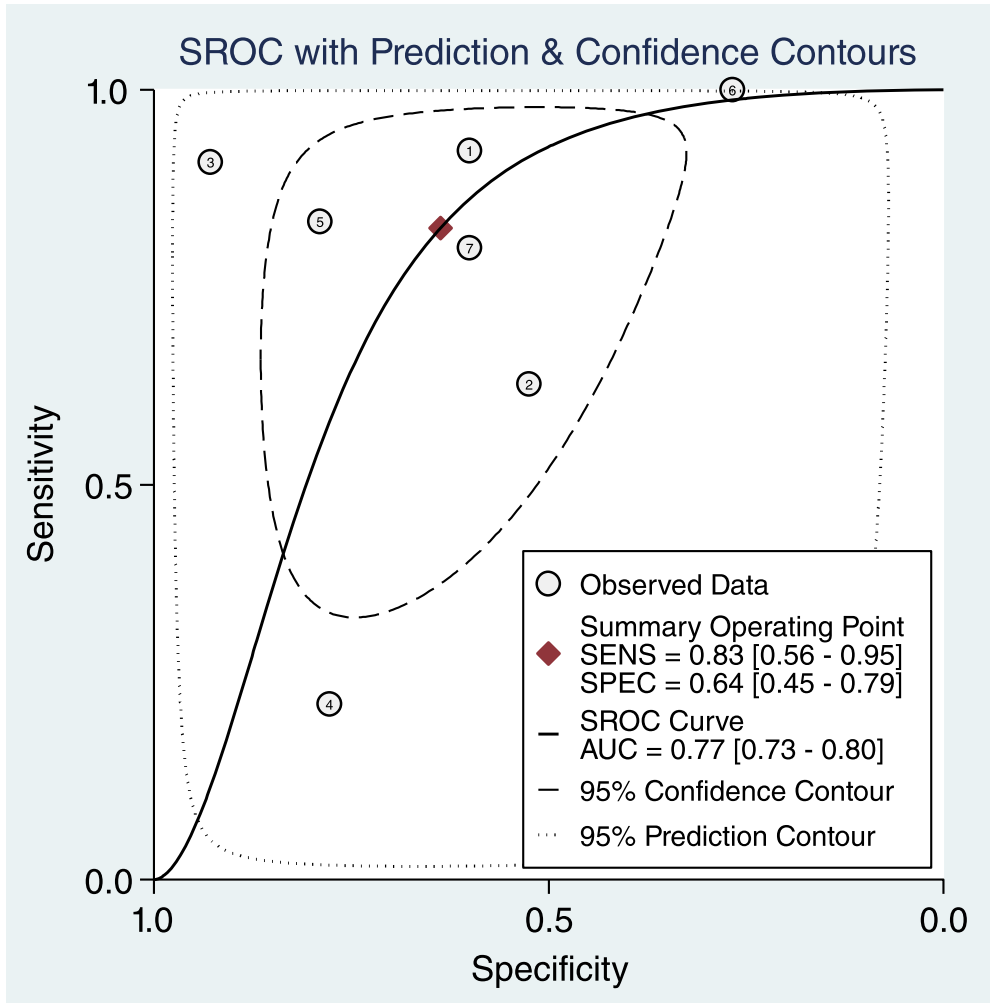

Fig. $5 \mathrm{SROC}$ of $3 \mathrm{~cm}$ adrenal mass as the best cut-off in patients with adrenal incidentaloma with prior history of malignancy

irregularity and calcification does not show a potent positive and negative LR. Although usually the malignant masses are more heterogeneous with irregular margins, some benign masses can appear irregular as well $[45,46]$. The low strength likelihood ratios in the second group shows that appearance of the mass cannot be so helpful to differentiate malignant lesions in patients with extra-adrenal malignancy because of higher prevalence of metastatic lesions in this group which can be similar in appearance with adenoma, which shows similarity with previous findings [18].

In this study in the first group without history of neoplasm in $10 \mathrm{HU}$ cut-off for density a positive and negative
LR of 2.85 and 0 was found. Hounsfield unit of the mass is considered a parameter as important as the size or even more important to distinguish malignant masses $[8,45]$ The density of $10 \mathrm{HU}$ is reported as the best cut-off for diagnosis of malignancy according to the previous studies [45, 47-50]. In a meta-analysis in 1998 Boland et al. found a sensitivity of $71 \%$ and a specificity of $98 \%$ with $10 \mathrm{HU}$ cut-off as the best diagnostic threshold [56]. In the second group a positive and negative LR of 3.6 and 0.08 for the density of $20 \mathrm{HU}$ was the result of the present study. Based on a review on previous studies the best mass density to be chosen as treatment cut-off is $20 \mathrm{HU}$ in patients with previous malignancy history [44]. Hamrahian et al. in

Table 4 LR for mass appearance: Pooled estimate of sensitivity, specificity, positive and negative LR based on appearance characteristics of the adrenal mass in patients with or without prior history of malignancy

\begin{tabular}{|c|c|c|c|c|c|c|c|}
\hline Mass appearance & History of malignancy & No of studies & $\begin{array}{l}\text { Co-sensitivity } \\
(95 \% \text { Cl) }\end{array}$ & $\begin{array}{l}\text { Co-specificity } \\
(95 \% \mathrm{Cl})\end{array}$ & $\mathrm{I}^{2}(95 \% \mathrm{Cl})$ & Pooled positive LR & Pooled negative LR \\
\hline Heterogeneity & No & 3 & $0.79,0.93,0.75$ & $0.71,1,0.78$ & - & $2.72, \infty, 3.4$ & $0.29,0.07,0.32$ \\
\hline Irregularity & No & 2 & $0.41,0.5$ & $0.93,0.98$ & - & $5.85,0.45$ & 0.63 \\
\hline Rough margin & No & 1 & 0.56 & 0.9 & - & 5.6 & 0.48 \\
\hline Heterogeneity & Yes & 6 & $0.38,(0.22-0.57)$ & $0.76,(0.66-0.84)$ & $55,(0-100)$ & $1.6,(0.8-3.2)$ & $0.81,(0.57-1.16)$ \\
\hline Rough margin & Yes & 1 & 0.37 & 1 & - & $\infty$ & 0.63 \\
\hline Calcification & Yes & 2 & $0.21,1$ & $0.92,0.17$ & - & $2.62,1.2$ & $0.85,0$ \\
\hline
\end{tabular}

$\infty$ It indicates significantly high positive LR 
Table $\mathbf{5}$ LR for mass density. Pooled estimate of sensitivity, specificity, positive and negative LR based on density of the adrenal mass in patients with or without prior history of malignancy

\begin{tabular}{|c|c|c|c|c|c|c|c|}
\hline $\begin{array}{l}\text { Mass density cut- } \\
\text { off }\end{array}$ & $\begin{array}{l}\text { History of } \\
\text { malignancy }\end{array}$ & $\begin{array}{l}\text { No of } \\
\text { studies }\end{array}$ & $\begin{array}{l}\text { Co-sensitivity (95 \% } \\
\text { Cl) }\end{array}$ & $\begin{array}{l}\text { Co-specificity (95 \% } \\
\mathrm{Cl})\end{array}$ & $1^{2}(95 \% \mathrm{Cl})$ & $\begin{array}{l}\text { Pooled positive } \\
\text { LR }\end{array}$ & $\begin{array}{l}\text { Pooled negative } \\
\text { LR }\end{array}$ \\
\hline $10 \mathrm{HU}$ & No & 1 & 1 & 0.65 & - & 2.85 & 0 \\
\hline $16 \mathrm{HU}$ & No & 1 & 0.95 & 1 & - & $\infty$ & 0.05 \\
\hline $20 \mathrm{HU}$ & No & 1 & 1 & 0.81 & - & 5.26 & 0 \\
\hline $\mathrm{OHU}$ & Yes & 3 & $1,1,1$ & $0.47,0.72,0.33$ & - & $1.88,3.57,1.49$ & $0,0,0$ \\
\hline $10 \mathrm{HU}$ & Yes & 7 & $0.96,(0.86-0.99)$ & $0.52,(0.39-0.64)$ & $\begin{array}{l}77,(50- \\
100)\end{array}$ & $2,(1.5-2.6)$ & $0.08,(0.02-0.3)$ \\
\hline $11 \mathrm{HU}$ & Yes & 1 & 1 & 0.55 & - & 2.22 & 0 \\
\hline $13 \mathrm{HU}$ & Yes & 1 & 1 & 1 & - & $\infty$ & 0 \\
\hline $15 \mathrm{HU}$ & Yes & 1 & 1 & 0.64 & - & 2.77 & 0 \\
\hline $18 \mathrm{HU}$ & Yes & 1 & 0.95 & 0.82 & - & 5.27 & 0.06 \\
\hline $20 \mathrm{HU}$ & Yes & 4 & $0.94,(0.80-0.98)$ & $0.74,(0.46-0.90)$ & $\begin{array}{l}87,(73- \\
100)\end{array}$ & 3.6, (1.6-8.3) & $0.08,(0.03-0.24)$ \\
\hline $21 \mathrm{HU}$ & Yes & 1 & 0.89 & 1 & - & $\infty$ & 0.11 \\
\hline $25 \mathrm{HU}$ & Yes & 1 & 0.95 & 0.72 & - & 3.39 & 0.06 \\
\hline $35 \mathrm{HU}$ & Yes & 1 & 0.54 & 1 & - & $\infty$ & 0.46 \\
\hline
\end{tabular}

$\infty$ It indicates significantly high positive LR

2005 proposed $20 \mathrm{HU}$ density cut-off to perform operation in case of lower sized masses in patients with prior malignancy as well, although in that study the size threshold for operation is suggested to be $4 \mathrm{~cm}$ [57].

Mass washout in dynamic CT scanning is another factor that can differentiate malignancy; however just the positive and negative LR are reported in this study due to low number of articles considering this factor and wide range of techniques and cut-offs.

In the first group truly diagnosed with adrenal incidentaloma, with a treatment threshold of $25 \%$ to perform operation [7], the results show a lower treatment threshold of $3 \%$ and upper treatment threshold of $52 \%$ for $4 \mathrm{~cm}$ cutoff. In previous studies prevalence of malignancy among

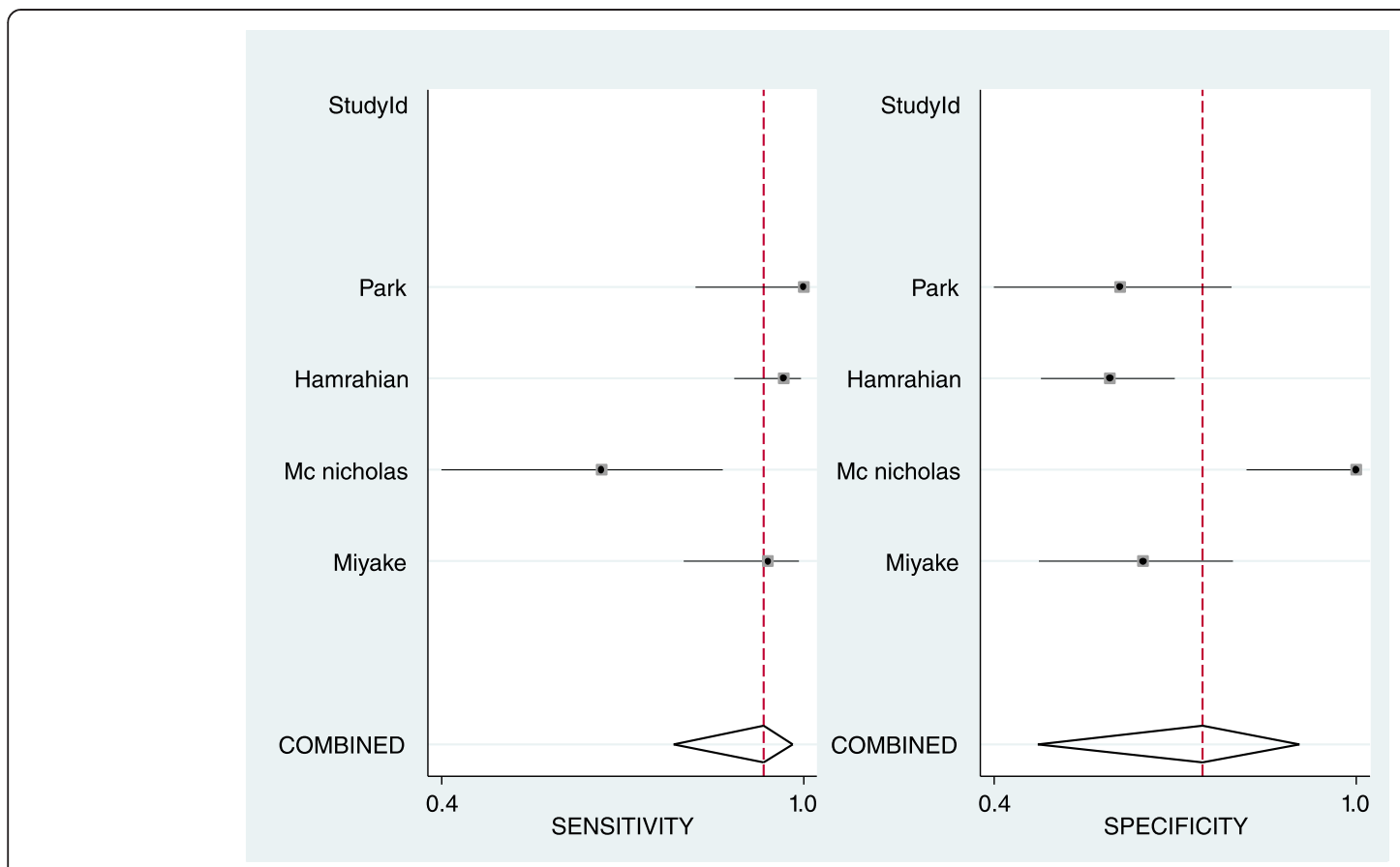

Fig. 6 Forest plot of $20 \mathrm{HU}$ adrenal mass as the best cut-off for densityin patients with adrenal incidentaloma with prior history of malignancy 


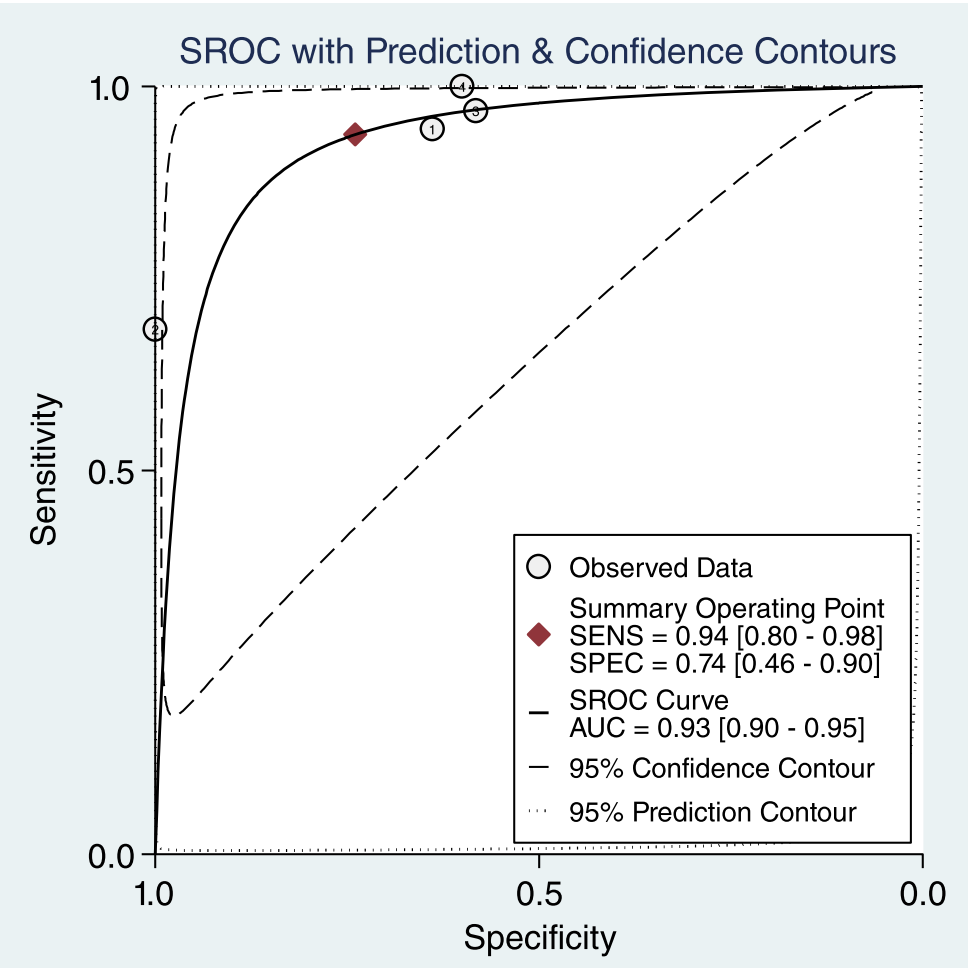

Fig. 7 SROC of $20 \mathrm{HU}$ adrenal mass as the best cut-off for density in patients with adrenal incidentaloma with prior history of malignancy

adrenal masses including metastasis and primary adrenal tumor is reported with a range of 2.7 to $13 \%$ in patients without extra-adrenal malignancy $[8,18,29,46,47,58]$. In the studies with more restricted definition for adrenal incidentaloma a lower prevalence is reported while the reports show higher prevalence in surgical series. So the pretest probability of malignancy in true adrenal incidentalomas is assumed to be $5 \%$ as an average in this study. The results (Fig. 8) confirms previous studies which mention that the size of the adrenal mass alone cannot be an indicator for malignancy because masses larger than $4 \mathrm{~cm}$ do not pass any treatment threshold $[7,26,47]$. In this condition another factor that can be diagnostic is the density of the mass in CT scan which is introduced as the best characteristic to diagnose malignancy in some studies $[8,45]$.

In the second group with extra adrenal neoplasm the treatment threshold is estimated $25 \%$ [7]. In size cut-off of $3 \mathrm{~cm}$ as the best threshold for malignancy, there are a lower and upper treatment threshold of 8 and $43 \%$. The prevalence of metastasis and primary adrenal carcinoma in this group ranges from 19 to $75 \%$ according to the literature [3, 7, 8, 15-18, 44, 59]. Although some studies indicate that the prevalence of metastasis in patients with a known neoplasm reaches 26 to $36 \%$ [60]. Regardless of this wide range $50 \%$ is chosen as pretest probability of malignancy in this group based on the most frequent reports.

\section{Conclusion}

As a conclusion, an evidence based flowchart is suggested in which among the patients without history of malignancy adrenal masses smaller than $4 \mathrm{~cm}$ or the ones larger than $4 \mathrm{~cm}$ with density of less than $10 \mathrm{HU}$ can be just followed up but the lesions larger than $4 \mathrm{~cm}$ with density more than $10 \mathrm{HU}$ should be gone under additional diagnostic procedure. In patients with prior

Table 6 LR for mass enhancement. Pooled estimate of sensitivity, specificity, positive and negative LR based on enhancement of the adrenal mass in patients with prior history of malignancy

\begin{tabular}{|c|c|c|c|c|c|c|}
\hline Mass character & History of malignancy & No of studies & Sensitivity & Specificity & Positive LR & Negative LR \\
\hline RPW 10 min delay (37.5\%) & Yes & 1 & 1 & 0.95 & 20 & 0 \\
\hline APW 10 min delay (52\%) & Yes & 1 & 1 & 0.98 & 50 & 0 \\
\hline Contrast enhancement & Yes & 1 & 0.74 & 0.83 & 4.35 & 0.31 \\
\hline
\end{tabular}




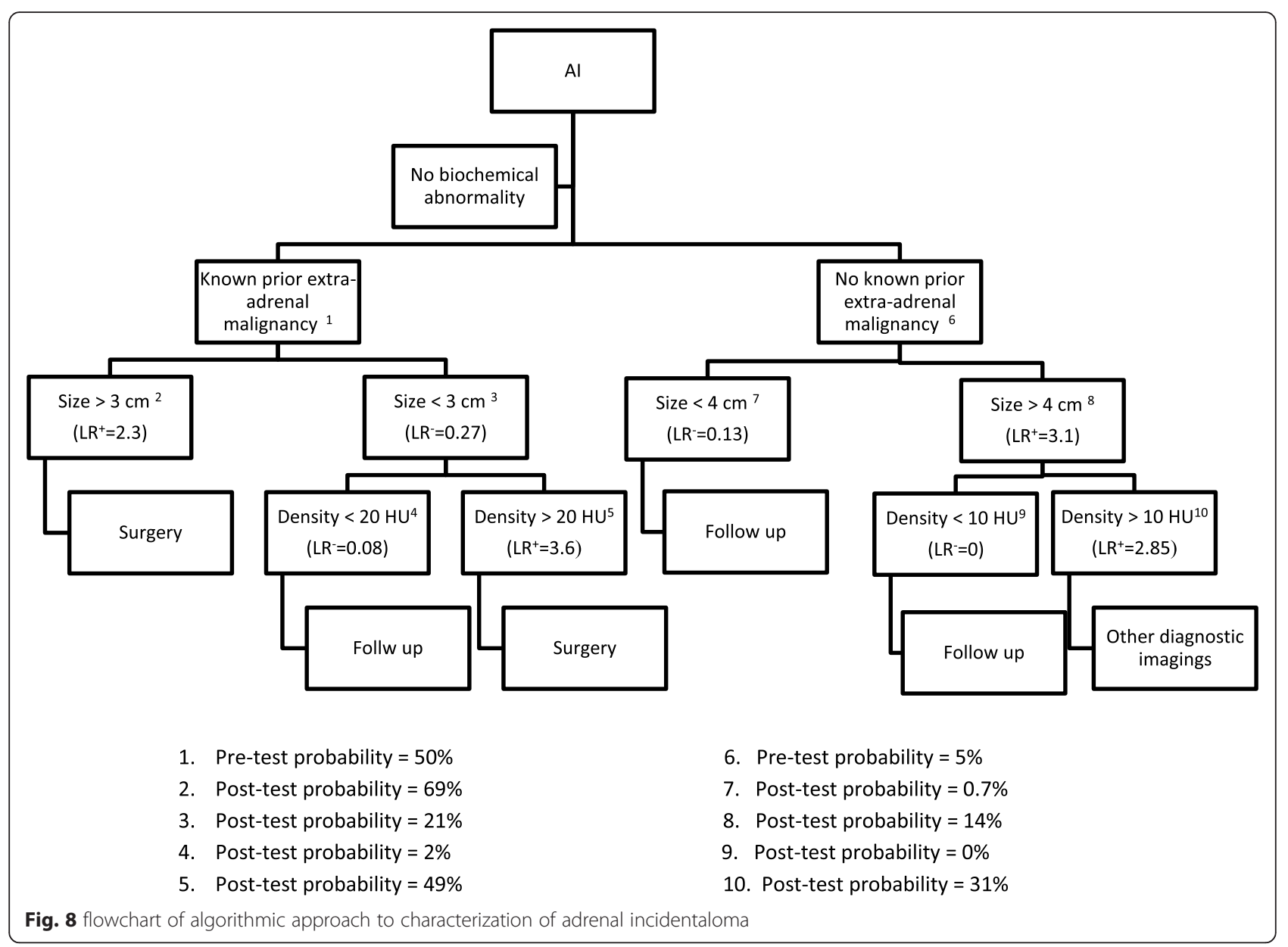

malignancy the masses larger than $3 \mathrm{~cm}$ or smaller than $3 \mathrm{~cm}$ with density more than $20 \mathrm{HU}$ should be resected through surgery but the ones less than $3 \mathrm{~cm}$ with density less than $20 \mathrm{HU}$ can be followed-up (Fig. 8).

Some limitations in this study should be considered. First, the articles are limited to English language and though the search was continued until no new article was found, there may be some studies left including conference presentation because of limitation of the search to Medline database. Second, the articles included are heterogeneous in results so the "random-effect" analysis was performed. Third, because of differences in results reported in studies in differentiation between malignant masses and non-malignant ones or adenoma and nonadenoma both were considered the same in this study to avoid several categorizations and low number of articles in each group. Forth, the studies in which functional masses and non-functional ones had not been separated were not excluded from the study. Fifth, there are reports showing that some of the adrenal metastatic lesions may not be detected within a 6 month follow up period so this diagnosing tool may not be a gold standard to detect malignancy in patients with history of neoplasm.
Although this study attempted to provide an evidencebased algorithm for approaching adrenal incidentaloma, considering its limitations, similar systematic reviews are needed to be conducted in future to collect higher number of studies. In addition, because many adrenal masses are found incidentally by other imaging methods such as MRI and Ultrasonography, assessing their ability to distinguish malignancy would be beneficial.

\section{Ethics approval}

Not Applicable.

\section{Consent for publication \\ Not Applicable.}

\section{Availability of data}

Available on request.

\section{Abbreviations}

AUC: area under the curve; $C T$ : computed tomography; FN: false negative; FP: false positive; HU: Hounsfield Unit; LR: likelihood ratio; QUADAS: Quality Assessment of Diagnostic Accuracy Studies; SROC: Summary Roc Curve; TN: true negative; TP: true positive. 


\section{Competing interests}

The authors declare that they have no competing interests.

\section{Authors' contributions}

FS: Study design, Data acquisition, Quality control of data and algorithms, Data analysis and interpretation, Statistical analysis, Manuscript preparation, Manuscript editing, Manuscript review. RM: Study design, Quality control of data and algorithms, Data analysis and interpretation, Statistical analysis, Manuscript editing, Manuscript review. BM: Study design, Data acquisition, Quality control of data and algorithms, Statistical analysis, Manuscript editing, Manuscript review. KH: Study design, Data acquisition, Data analysis and interpretation, Statistical analysis, Manuscript editing, Manuscript review. AS: Study concepts, Study design, Quality control of data and algorithms, Data analysis and interpretation, Statistical analysis, Manuscript editing, Manuscript review. All authors read and approved the final manuscript.

\section{Funding}

No funding body

\section{Author details}

${ }^{1}$ School of Medicine and Public Health, Evidence based Practice Research Center, Tehran University of Medical Sciences, Tehran, Iran. ${ }^{2}$ Center for Knowledge Translation and Exchange, Tehran University of Medical Sciences, School of Public Health, Tehran, Iran. ${ }^{3}$ Evidence based Practice Research Center, Endocrinology and Metabolism Research Center, Tehran University of Medical Sciences, Tehran, Iran. ${ }^{4}$ School of public health, Tehran University of Medical Sciences, Tehran, Iran.

\section{Received: 13 August 2015 Accepted: 24 February 2016}

\section{Published online: 21 April 2016}

\section{References}

1. Al-Hawary MM, Francis IR, Korobkin M. Non-invasive evaluation of the incidentally detected indeterminate adrenal mass. Best Pract Res Clin Endocrinol Metab. 2005;19(2):277-92.

2. Gross MD, Shapiro B. Clinical review 50 clinically silent adrenal masses. J Clin Endocrinol Metabol. 1993;77(4):885-8.

3. Kloos RT, Gross MD, Francis IR, Korobkin M, Shapiro B. Incidentally discovered adrenal masses. Endocr Rev. 1995;16(4):460-84.

4. Mantero F, Albiger N. A comprehensive approach to adrenal incidentalomas. Arq Bras Endocrinol Metab. 2004:48(5):583-91.

5. Mantero F, Arnaldi G. Management approaches to adrenal incidentaloma, a view from Ancona Italy. Endocrinol Metab Clin. 2000:29(1):107-25.

6. Kawashima A, Sandler CM, Fishman EK, et al. Spectrum of CT findings in nonmalignant disease of the adrenal gland. Radiographics. 1998;18(2):393-412.

7. NIH State-of-the-Science Statement on Management of the Clinically Inapparent Adrenal Mass ("Incidentaloma"). NIH Consensus State Sci Statements. 2002;19(2):1-25

8. Terzolo M, Stigliano A, Chiodini I, et al. AME position statement on adrenal incidentaloma. Eur J Endocrinol. 2011;164(6):851-70.

9. Aron DC. The adrenal incidentaloma: disease of modern technology and public health problem. Rev Endocr Metab Disord. 2001;2(3):335-42.

10. Peppercorn PD, Grossman AB, Reznek RH. Imaging of incidentally discovered adrenal masses. Clin Endocrinol (Oxf). 1998:48(4):379-88.

11. Nishikawa T, Saito J, Omura M. Section 3. Adrenal mini review: surgical indications for adrenal incidentaloma. Biomed Pharmacother. 2002;56 suppl 1:145-8.

12. Moreira SG, Pow-Sang JM. Evaluation and management of adrenal masses Cancer Control. 2002:9(4):326-34.

13. Thompson GB, Young WF. Adrenal incidentaloma. Curr Opin Oncol. 2003; 15(1):84-90.

14. Mantero F, Arnaldi G. Investigation protocol: adrenal enlargement. Clin Endocrinol (Oxf). 1999:50(2):141-6.

15. Mansmann G, Lau J, Balk E, Rothberg M, Miyachi Y, Bornstein SR. The clinically inapparent adrenal mass: update in diagnosis and management. Endocr Rev. 2004:25(2):309-40.

16. Sahdev A, Reznek RH. Imaging evaluation of the nonfunctioning indeterminate adrenal mass. Trends Endocrinol Metab. 2004:15(6):271-6.

17. Pender SM, Boland GW, Lee MJ. The incidental nonhyperfunctioning adrenal mass: an imaging algorithm for characterization. Clin Radiol. 1998; 53(11):796-804.
18. Boland GWL, Blake MA, Hahn PF, Mayo-smith WW. Incidental adrenal lesion: principles, techniques and algorithms for imaging characterization. Radiology. 2008;249(3):756-75.

19. Staren ED, Prinz RA. Selection of patients with adrenal incidentaloma for operation. Surg Clin North Am. 1995;75(3):499-509.

20. Schteingart DE. Management approaches to adrenal incidentaloma, a view from Ann Arbor Michigan. Endocrinol Metab Clin North Am. 2000;29(1):127-39.

21. Munver R, Fromer DL, Watson RA, Sawczuk IS. Evaluation of the incidentally discovered adrenal mass. Curr Urol Rep. 2004;5(1):73-7.

22. Lee M, Mayo-Smith WW, Hahn PF, Goldberg MA, Boland GW, Saini S, Papanicolaou N. State-of-the-Art MR imaging of the adrenal. Radiographics. 1994;14(5):1015-29.

23. Korobkin M, Francis IR. Adrenal imaging. Semin Ultrasound CT MRI. 1995; 16(4):317-30.

24. Cook DM, Loriaux DL. The incidental adrenal mass. Am J Med. 1996:101(1):88-94

25. Lockhart ME, Smith JK, Kenney PJ. Imaging of adrenal masses. Eur J Radiol. 2002:41(2):95-112.

26. Bernardino ME. Management of the asymptomatic patient with a unilateral adrenal mass. Radiology. 1988;166:121-3.

27. Brunt LM, Moley JF. Adrenal incidentaloma. World J Surg. 2001;25:905-13.

28. Cook DM. Adrenal mass. Endocrinol Metab Clin North Am. 1997;26(4):829-52.

29. Cawood TJ, Hunt PJ, O'Shea D, Cole D, Soule S. Recommended evaluation of adrenal incidentalomas is costly, has high false-positive rates and confers a risk of fatal cancer that is similar to the risk of the adrenal lesion becoming malignant; time for a rethink? Eur J Endocrinol. 2009;161(4):513-27.

30. Simel DL, Rennie D. The rational clinical examination. Evidence-based clinical diagnosis. New York: McGrowHill mediacal; 1995.

31. Loriaux DL. Chapter 84. The incidental adrenal mass. Becker KL. Principals and practice of endocrinology and metabolism. Philadelphia:. Lippincott Williams and Wilkins. 2002;p. 816-7.

32. Miller DL. Chapter 88. Diagnostic imaging of the adrenal gland. Becker KL. Principals and practice of endocrinology and metabolism. Philadelphia:. Lippincott Williams and Wilkins. 2002;p. 837-45.

33. Doppman JL. Adrenal gland and glucocorticoids. Chapter 125. Adrenal imaging. In:Degroot $\sqcup$, Jameson $J$, editors. Endocrinology. Philadelphia: WB Saunders. 2011;p. 1761-6.

34. Williams RH, Larsen PR. Williams textbook of endocrinology. Philadelphia, PA: Elsevier Science Health Science Division. 2008.

35. Whiting P, Rutjes AWS, Reitsma JB, Bossuyt PMM, Kleijnen J. The development of QUADAS: a tool for the quality assessment of studies of diagnostic accuracy included in systematic reviews. BMC Med Res Methodol. 2003;3(25):1-13.

36. StataCorp. 2009. Stata Statistical Software: Release 11. College Station, TX: StataCorp LP.

37. Macaskill P, Gatsonis C, Deeks JJ, Harbord RM, Takwoingi Y. Chapter 10: Analysing and Presenting Results. In: Deeks JJ, Bossuyt PM, Gatsonis C, editors. Cochrane Handbook for Systematic Reviews of Diagnostic Test Accuracy Version 1.0. The Cochrane Collaboration, 2010. Available from: http://methods.cochrane.org/sdt/handbook-dta-reviews.

38. Szolar DH, Kammerhuber FH. Adrenal adenomas and nonadenomas: assessment of washout at delayed contrast enhanced CT. Radiology. 1998;207(2):369-75.

39. Szolar DH, Kammerhuber F. Quantitative CT evaluation of adrenal gland masses: a step forward in the differentiation between adenomas and nonadenomas? Radiology. 1997;202(2):517-21.

40. Paivansalo M, Lahde S, Merikanto $\sqcup$, Kallionen M. Computed tomography in primary and secondary adrenal tumours. Acta Radiol. 1998;29(5):519-22.

41. Katz RL, Shirkhoda A. Diagnostic approach to incidental adrenal nodules in the cancer patient. Cancer. 1985;55(9):1995-2000.

42. Hussain S, Belldegrun A, Seltzer SE, Richie JP, Gittes RF, Abrams HL. Differentiation of malignant from benign adrenal masses: predictive indices on computed tomography. AJR Am J Roentgenol. 1985;144(1):61-5.

43. Gopan T, Remer E, Hamrahian AH. Evaluating and managing adrenal incidentaloma. Cleve Clin J Med. 2006;73(6):561-8.

44. Terzolo M, Bovio S, Pia A, Reimondo G, Angeli A. Management of adrenal incidentaloma. Best Pract Res Clin Endocrinol Metab. 2009:23(2):233-43.

45. Boland GWL. Adrenal imaging: why, when, what, and how? Part 3. The algorithmic approach to definitive characterization of the adrenal incidentaloma. AJR Am J Roentgenol. 2011;196(2):W109-W111.

46. Ridho FE, Adam FMS, Adam JMF. Adrenal incidentaloma. Acta Med Indones. 2009;41(2):87-93. 
47. Anagnostis P, Karagiannis A, Tziomalos K, Kakafika Al, Athyros VG, Mikhailidis DP. Adrenal incidentaloma: a diagnostic challenge. Hormones. 2009;8(3):163-84

48. Song JH, Mayo-Smith WW. Incidentally discovered adrenal mass. Radiol Clin N Am. 2011;49(2):361-8.

49. Heinz-Peer G, Memarsadeghi M, Niederle B. Imaging of adrenal masses. Curr Opin Urol. 2007;17(1):32-8.

50. Ozturk $\mathrm{E}$, Sildiroglu HO, Kantarci $\mathrm{M}$, et al. Computed tomography findings in diseases of the adrenal gland. Wien Klin Wochenschr. 2009;121:372-81.

51. McNicholas MMJ, Lee MJ, Mayo-Smith WW, Hahn PF, Boband GW, Mueller PR. An imaging algorithm for the differential diagnosis of adrenal adenomas and metastases. AJR Am J Roentgenol. 1995;165(6):1453-9.

52. McGrath PC, Sloan DA, Schwartz RW, Kenady DE. Advances in the diagnosis and therapy of adrenal tumors. Curr Opin Oncol. 1998;10(1):52-7.

53. Hamrahian AH, loachimescu AG, Remer EM, et al. Clinical utility of noncontrast computed tomography attenuation value (Hounsfield units) to differentiate adrenal adenomas/hyperplasias from nonadenomas: Cleveland clinic experience. J Clin Endocrinol Metab. 2005;90(2):871-7.

54. Gufler H, Eichner G, Grossmann A, Krentz H, Schulze CG, Sauer S, Grau G. Differentiation of adrenal adenomas from metastases with unenhanced computed tomography. J Comput Assist Tomogr. 2004;28(6):818-22.

55. Hubbard MM, Husami TW, Abumrad NN. Nonfunctioning adrenal tumors dilemmas in management. Am Surg. 1989;55(8):516-22.

56. Boland GWL, Lee MJ, Gazelle GS, Halpern EF, Mc Nicholas MMJ, Muller PR. Characterization of adrenal masses using unenhanced $C T$ : an analysis of the CT literature. AJR Am J Roentgenol. 1998;171(1):201-4.

57. Bulow B, Ahren B. Adrenal incidentaloma - experience of a standardized diagnostic programme in the Swedish prospective study. J Intern Med. 2002;252(3):239-46.

58. Androulakis II, Kaltsas G, Piaditis G, Grossman AB. The clinical significance of adrenal incidentalomas. Eur J Clin Invest. 2011;41(5):552-60.

59. Gross MD, Korobkin M, Assaly WB, Dwamena B, Djekidel M. Contemporary imaging of incidentally discovered adrenal masses. Nat Rev Urol. 2009;6:363-73.

60. Sahdev A, Reznek RH. The indeterminate adrenal mass in patients with cancer. Cancer Imaging. 2007;7:S100-9.

61. Birsen $\mathrm{O}$, Akyuz M, Dural C, et al. A new risk stratification algorithm for the management of patients with adrenal incidentalomas. Surgery. 2014;156(4):959-66.

62. Reginelli A, Di Grezia G, Izzo A, et al. Imaging of adrenal incidentaloma: Our experience. Int J Surg. 2014;12:S126-31.

63. Allan B, Thorson C, Van Haren R, Parikh P, Lew J. Risk of concomitant malignancy in hyperfunctioning adrenal incidentalomas. J Surg Res. 2013; 184(1):241-6.

64. Hennings J, Hellman P, Alstrom H, Sundin A. Computed tomography, magnetic resonance imaging and $11 \mathrm{C}$-metomidate positron emission tomography for evaluation of adrenal incidentalomas. Eur J Radiol. 2009; 69(2):314-23.

65. Bhargav PRK, Mishra A, Agarwal G, Agarwal A, Verma AK, Mishra SK. Adrenal incidentalomas: experience in a developing country. World J Surg. 2008; 32(8):1802-8.

66. Vilar L, Freitas MC, Canadas V, et al. Adrenal incidentalomas: diagnostic evaluation and long-term follow-up. Endocr Pract. 2008:14(3):269-78

67. Park SH, Kim MJ, Kim JH, Lim JS, Kim KW. Differentiation of adrenal adenoma and nonadenoma in unenhanced CT: new optimal threshold value and the usefulness of size criteria for differentiation. Korean J Radiol. 2007;8(4):328-35.

68. Blake MA, Kalra MK, Sweeney AT, et al. Distinguishing benign from malignant adrenal masses: multi-detector row CT protocol with 10-minute delay. Radiology. 2006;238(2):578-85.

69. Meyer A, Behrend M. Indications and results of surgery for incidentally found adrenal tumors. Urol Int. 2006;77(2):173-8.

70. Frilling A, Tecklenborg K, Weber F, Kuhl H, Muller S, Stamatis G, Broelsch C. Importance of adrenal incidentaloma in patients with a history of malignancy. Surgery. 2004;136(6):1289-96.

71. Mantero F, Terzolo M, Arnaldi G, et al. A survey on adrenal incidentaloma in Italy. J Clin Endocrinol Metab. 2000;85:637-44.

72. Bergstrom M, Juhlin C, Bonasera TA, Sundin A, Rastad J, Akerstrom G, Langstrom B. PET imaging of adrenal cortical tumors with the $11 \mathrm{a}-$ HydroxylaseTracer 11C-metomidate. J Nucleic Med. 2000;41(2):275-82.
73. Sworczak K, Babisiska A, Stanek A, et al. Clinical and histopathological evaluation of the adrenal incidentaloma. Neoplasma. 2001:48(3):221-6.

74. Tutuncu NB, Gedik O. Adrenal incidentaloma: report of 33 cases. J Surg Oncol. 1999;70(4):247-50.

75. Kasperlik-zaluska AA, Roslonowska E, Slowinska-srzednicka J, Migdalska B, Jeske W, Makowska A, Snochowska H. Incidentally discovered adrenal mass (incidentaloma): investigation and management of 208 patients. Clin Endocrinol (Oxf). 1997;46(1):29-37.

76. Boland GW, Hahn PF, Pena C, Mueller PR. Adrenal masses: characterization with delayed contrast-enhanced CT. Radiology. 1997;202(3):693-6.

77. Angeli A, Osella G, Ali A, Terzolo M. Adrenal Incidentaloma: an overview of clinical and epidemiological data from the national Italian study group. Horm Res. 1997:47(4-6):279-83.

78. Miyake H, Takaki H, Matsumoto S, Yoshida S, Maeda T, Mori H. Adrenal nonhyperfunctioning adenoma and nonadenoma: CT attenuation value as discriminative index. Abdom Imaging. 1995;20(6):559-62.

79. Singer AA, Obuchowski NA, Einstein DM, Paushter DM. Metastasis or adenoma? Computed tomographic evaluation of the adrenal mass. Cleve Clin J Med. 1994;61(3):200-5.

80. Van Erkel AR, Van Gils APG, Lequin M, Kruitwagen C, Bloem JL, Falke THM. CT and MR distinction of adenoma and nonadenoma of adrenal gland. J Comput Assist Tomogr. 1994;18(3):432-8.

81. Candel AG, Gattuso P, Reyes CV, Prinz RA, Castelli MJ. Fine-needle aspiration biopsy of adrenal masses in patients with extra adrenal malignancy. Surgery. 1993;114(6):1132-7.

82. Semelka RC, Shoenut JP, Lawrence PH, Greenberg HM, Maycher B, Madden TP,Kroeker MA. Evaluation of adrenal masses with gadolinium enhancement and fat-suppressed MR imaging. J MRI. 1993;3(2):337-43.

83. Lee MJ, Hahn PF, Papanicolaou N, Egglin TK, Saini S, Mueller PR, Simeone JF. Benign and malignant adrenal masses: CT distinction with attenuation coefficients, size, and observer analysis. Radiology. 1991;179(2):415-8.

84. Herrera MF, Grant CS, van Heerden JA, Sheedy PF, Ilstrup DM. Incidentally discovered adrenal tumors: an institutional perspective. Surgery. 1991;110(6):1014-21.

85. Yamakita N, Saitoh M, Mercado-asis LB, Kitada M, Morita H, Yasuda K, Miura K. Asymptomatic adrenal tumor; 386 cases in japan including our 7 cases. Endocrinol Japan. 1990;37(5):671-84.

86. Lopez JM, Fardella C, Arteaga E, Michaud P, Rodriguez JA, Cruz F. Adrenal macrotumors diagnosed by computed tomography. J Endocrinol Invest. 1990;13(7):581-5.

\section{Submit your next manuscript to BioMed Central and we will help you at every step:}

- We accept pre-submission inquiries

- Our selector tool helps you to find the most relevant journal

- We provide round the clock customer support

- Convenient online submission

- Thorough peer review

- Inclusion in PubMed and all major indexing services

- Maximum visibility for your research

Submit your manuscript at www.biomedcentral.com/submit 